\section{Self-reported physical inactivity and health complaints: a cross-sectional study of Lithuanian adolescent schoolgirls}

\author{
Autorrelato de queixas de inatividade e saúde \\ física: um estudo transversal entre adolescentes
}

\author{
Autoinforme sobre la inactividad física y quejas de \\ salud: un estudio transversal entre las adolescentes
}

\author{
${ }^{1}$ Lithuanian Sports \\ University, Kaunas, \\ Lithuania. \\ Correspondence \\ R. Malinauskas \\ Lithuanian Sports University. \\ Sporto 6, Kaunas, \\ Lithuania - 44221 \\ romas.malinauskas@lsu.lt
}

\begin{abstract}
The study aimed to investigate the associations between physical inactivity and health complaints in relation to posttraumatic stress (PTS) symptoms, behavioral and nutritional factors, and sense of coherence (SOC) in eighth-grade girls enrolled in secondary schools in Kaunas, Lithuania. A random sample of girls $(N=862)$ was interviewed anonymously on health complaints, physical activity level, PTS symptoms, Antonovsky's SOC scale, health behaviors, and dietary patterns. All health complaints were significantly associated with physical inactivity. Crude odds ratio (OR) for physical inactivity and health complaints was 1.67 (95\%CI: 1.092.56); after adjusting for PTS symptoms, the OR decreased to 1.57 (95\%CI: 0.95-2.45); further adjustment for smoking, daily alcohol intake, daily consumption of fresh vegetables, and SOC decreased the OR to 1.25 (95\%CI: 0.76-2.04). The effect of PTS symptoms and sense of coherence remained stable after all adjustments. The significant association between physical inactivity and health complaints was mediated by PTS symptoms.
\end{abstract}

Motor Activity; Post-Traumatic Stress Disorders; Adolescent
Romualdas Malinauskas 1

Vilija Malinauskaiene 1

\section{Resumo}

O estudo tem como objetivo investigar a associação entre queixas de inatividade e saúde física em relação ao transtorno do estresse póstraumático (TEPT), sintomas comportamentais e fatores nutricionais, bem como o senso de coerência (SOC) entre alunas da oitava série. Uma amostra aleatória de alunas $(N=862)$ foi entrevistada anonimamente sobre: queixas de saúde, nível de atividade física, sintomas de TEPT, escala SOC de Antonousky, comportamentos de saúde e padrões alimentares. Todas as queixas de saúde foram significativamente associadas à inatividade física. A razão de odds (OR) não ajustada de inatividade física para queixas de saúde foi de 1,67 (IC95\%: 1,09-2,56), e após o ajuste para os sintomas de TEPT reduziu para 1,57 (IC95\%: 0,95-2,45); somado-se o ajuste para tabagismo, ingestão de álcool diária, legumes frescos e redução da escala SOC, houve diminuição da OR para 1.25 (IC95\%: 0,76-2,04). Observou-se uma associação significativa entre as queixas de inatividade e de saúde física, mediadas pelos sintomas de TEPT.

Atividade Motora; Transtornos de Estresse Pós-Traumático; Adolescente 


\section{Introduction}

Studies have confirmed that physical activity moderates the relationship between school-related stress and health complaints in adolescents 1,2. However, according to the biopsychosocial process model of health and complaints in children and adolescents, a multi-level approach to "modifiable conditions" (e.g. intrinsic motivation to be physically active), physical activity, and eating patterns may lead to psychosomatic complaints (headache, backache, and stomachache, among others) ${ }^{3}$. A recent study showed a protective effect of moderate-to-vigorous physical activity in both sexes among adolescents for four health indicators (self-rated health, health complaints, satisfaction with life, and health-related quality of life) ${ }^{4}$. In the latter study, associations between physical activity and health complaints were adjusted for health behaviors (smoking, alcohol intake), body mass index (BMI), dietary patterns (consumption of fruit and vegetables), screen time (TV and/or computer), parents' socioeconomic status (SES), and satisfaction with family and friends, while the study did not allow predicting associations with poor mental health. A large Health Behavior in School-Aged Children (HBSC) survey in 20 European countries showed that socio-demographic factors were significant mediators of the associations between leisure-time physical activity and psychological complaints 5 , and again no potential mediation of poor mental health was investigated. Many traumatized children experience brief symptoms of depression, anxiety, or developmental regression but return to baseline quickly, whereas others suffer longstanding posttraumatic stress disorder (PTSD) as a consequence of childhood trauma. Adolescents with PTSD present prominent symptoms of nightmares, flashbacks, hyperarousal, avoidance of trauma reminders, and emotional numbing. Irritability, outbursts, and poor concentration are also common in PTSD 6 . Factors that emerge from the literature as significantly related to PTSD in adolescence include repeated trauma and health problems 7,8,9. Another study found that PTSD significantly predicted somatic complaints over time 10. Meanwhile, studies among adults show dose-response relationships between physical activity and overall mental health 11 . Therefore, in our study, we included posttraumatic stress (PTS) symptoms as an indicator of poor mental health, hypothesizing that PTS symptoms might mediate the associations between physical inactivity and health complaints among adolescent girls. The lack of findings on associations between physical inactivity and health complaints in relation to posttraumatic stress symptoms motivated the current study. Adolescent girls were chosen as the study population, since there are many studies conducted among boys but few among girls. Physical inactivity is also more prevalent in girls than in boys.

We aimed to test the hypothesis that physical inactivity is associated with health complaints in adolescent girls. We also investigated whether PTS symptoms mediate the associations between physical inactivity and health complaints, considering the possible effects of smoking, alcohol intake, and dietary patterns, since evidence suggests that these factors are related both to health problems 12,13 and to physical activity 14,15. Research has shown that adolescents with low sense of coherence (SOC) are more prone to depression, anxiety, and psychosomatic problems, while strong SOC was associated with more frequent physical exercise 16. Our next step was thus to show the effect of SOC in the associations between physical inactivity and health complaints in adolescent girls. The current study was mainly motivated by the lack of findings on this topic in the literature. The purpose was to emphasize practical implications in attempts to reduce health complaints among adolescent girls.

\section{Methods}

\section{Participants}

This cross-sectional study was conducted in a sample of 14-15-year-old eighth-grade girls selected from ten secondary schools in Kaunas, Lithuania, October to December 2012. The schools were randomly selected from 15 city districts in order to represent families' different socioeconomic strata. In a total of 60 classes, 1,015 girls were selected, and 862 who completed the entire questionnaire were included for analysis (response rate $84.9 \%$ ).

\section{Procedures}

Before beginning the study, ethical approval was obtained from the Regional Ethics Committee of the Lithuanian University of Health Sciences. Permission to conduct the study was also granted by school principals and the director of the Kaunas Educational Center. Data were collected from October to December 2012 using a questionnaire. The school nurse announced the study and explained the questionnaire and other relevant information to all pupils in grade eight during the class approximately one week before the health dialogue took place. All pupils and parents received written information about the purpose 
of the study, and girls who brought written permission from their parents participated. These pupils completed the questionnaires during the health dialogue.

\section{Measures}

\section{- Posttraumatic stress symptoms}

The Impact of Event Scale-Revised (IES-R) 17 was used to assess PTS symptoms, tracking lifetime traumatic experiences. The IES-R has 22 items which assess hyperarousal symptoms such as anger and irritability, heightened startle response, difficulty in concentrating and hypervigilance, while the intrusion subscale assesses dissociative-like re-experience and true flashbacks. Eight items are used to assess avoidance according to Diagnostic and Statistical Manual of Mental Disorders, $4^{\text {th }}$ edition (DSM-IV). Respondents were asked to rate each item according to the past seven days on a Likert scale with four possible answers. The scale was translated into Lithuanian and cultural adaptation was performed. Internal consistency of the total IES-R scale was high in the present study (Cronbach's alpha 0.95).

\section{- Physical activity}

Physical activity was assessed with a modified Godin leisure-time exercise questionnaire 18 . The scale contains three questions that assess the frequency of mild, moderate, and strenuous exercise for at least 15 minutes during a typical week. A total score is calculated in arbitrary units by weighting each frequency by an estimated intensity, guided by metabolic equivalents using the equation ( $9 \mathrm{X}$ strenuous $)+(5 \mathrm{X}$ moderate $)+(3 \mathrm{X}$ light). Total physical activity score was $67.1 \pm 32.8$. Study participants were assigned to three groups based on total physical activity score: girls with the highest tertile of total physical activity score were categorized as active (42.1-67.1), and those with the second highest tertile as moderately active (23.1-42.0). The others, in the lowest tertile of total physical activity, were categorized as insufficiently active $(\leq 23.0)$.

\section{- Sense of coherence}

Sense of coherence was measured by a 13-item version (with five possible answers in a positive direction) of the Antonovsky's SOC scale ${ }^{19}$. SOC is defined as the extent to which one has a pervasive, enduring (though dynamic) feeling of confidence that one's environment is predictable, and that things will work out as well as reasonably expected. All items were added and the total score was included for analysis as a continuous variable. The sum total ranged from 13 to 65 , with higher score corresponding to stronger sense of coherence. The scale's internal consistency was high (Cronbach's alpha 0.856). Lithuanian cultural adaptation of the scale was performed previously in a HBSC study 20 and showed good psychometric properties.

\section{- Health complaints}

Nine health complaints including headache, stomachache, sleep disturbance, and others were also selected from the HBSC study to estimate their frequency during the previous six months and were estimated on a 5-point Likert scale. Answers "more than once a week" and "daily" were considered positive. A summary variable was calculated with all nine health complaints and dichotomized as the group with at least one health complaint versus the group with no health complaints, and used in logistic regression models.

\section{- Statistical analysis}

SPSS for Windows version 20.0 (IBM Corp., Armonk, USA) was used in the statistical analysis. Descriptive statistics were compared using the chi-square test. Variables that were significantly associated with health complaints in the crude analyses were included in four logistic regression models. First, the associations between physical inactivity as independent variable and summed up and dichotomized health complaints as dependent variable and PTS symptoms (Model I), plus smoking and daily alcohol intake (Model II) were included in the analysis. Next, dietary pattern (no daily consumption of fresh vegetables) (Model III) and finally the adjustment for SOC as continuous variable (Model IV) was performed. The results are presented as odds ratios (OR) with 95\% confidence intervals (95\%CI).

\section{Results}

Table 1 shows the prevalence of all target factors and the associations between levels of physical activity and health complaints (more than once a week) and other variables.

Prevalence of PTS symptoms was $17.9 \%$. $12.2 \%$ of the girls were physically inactive. Prevalence of health complaints was high: one-fourth to one-fifth complained of headache, irritability and bad temper, nervousness, anxiety, sadness, or sleep disturbances. All the health complaints as well as PTS symptoms, smoking, daily alcohol intake, and no daily consumption of fresh vege- 
Table 1

Level of physical activity and physical health complaints in a sample of Lithuanian adolescent schoolgirls, 2012.

\begin{tabular}{|c|c|c|c|c|c|}
\hline \multirow[t]{2}{*}{ Health complaint } & \multirow[t]{2}{*}{ Prevalence (\%) } & \multirow[b]{2}{*}{ Active $(n=557)$} & \multicolumn{2}{|c|}{ Physical activity [n (\%)] } & \multirow[t]{2}{*}{$\mathrm{p}$-value } \\
\hline & & & $\begin{array}{l}\text { Moderately active } \\
\qquad(\mathrm{n}=200)\end{array}$ & $\begin{array}{l}\text { Insufficiently active } \\
\qquad(\mathrm{n}=105)\end{array}$ & \\
\hline Headache & $192(22.3)$ & $107(19.2)$ & $57(28.5)$ & $28(26.7)$ & 0.013 \\
\hline Stomachache & $90(10.4)$ & $51(9.2)$ & $20(10.0)$ & $19(18.1)$ & 0.022 \\
\hline Backache & $83(9.6)$ & $45(8.1)$ & $17(8.5)$ & $21(20.0)$ & $<0.001$ \\
\hline Anxiety and sadness & $162(18.8)$ & $89(16.0)$ & $43(21.5)$ & $30(28.6)$ & 0.005 \\
\hline Irritability or bad temper & $192(22.3)$ & $109(19.6)$ & $51(25.5)$ & $32(30.5)$ & 0.022 \\
\hline Nervousness & $177(20.5)$ & $94(16.9)$ & $55(27.5)$ & $28(26.7)$ & 0.002 \\
\hline Sleep disturbances & $159(18.4)$ & $87(15.6)$ & $41(20.5)$ & $31(29.5)$ & 0.002 \\
\hline Dizziness & $91(10.6)$ & $48(8.6)$ & $17(8.5)$ & $26(24.8)$ & $<0.0001$ \\
\hline Morning fatigue & 275 (31.9) & $158(28.4)$ & $76(38.0)$ & $41(39.0)$ & 0.011 \\
\hline PTS symptoms & $154(17.9)$ & $89(16.0)$ & $41(20.5)$ & $24(22.9)$ & 0.013 \\
\hline Smoking & $115(13.3)$ & $58(10.4)$ & $28(14.0)$ & $29(27.6)$ & $<0.0001$ \\
\hline Daily alcohol intake & $54(6.3)$ & $27(4.9)$ & $12(6.0)$ & $15(14.4)$ & $<0.001$ \\
\hline Daily fresh vegetables & $583(67.9)$ & $403(72.6)$ & $127(63.5)$ & $53(51.0)$ & $<0.0001$ \\
\hline
\end{tabular}

PTS: posttraumatic stress

tables were significantly and inversely associated with level of physical activity.

Table 2 shows the associations between physical inactivity and at least one health complaint (more than once a week) expressed as OR with $95 \%$ CI. For physical inactivity with health complaints as the dependent variable, the crude odds ratio was 1.67 (95\%CI: 1.09-2.56). After adjusting for PTS symptoms the OR decreased to 1.57 (95\%CI: 0.95-2.45). After further adjustment for smoking, daily alcohol intake, and daily consumption of fresh vegetables, the OR decreased to 1.34 , and finally, adjustment for SOC as a continuous variable decreased the OR to 1.25 (95\%CI: $0.76-2.04)$. The effect of PTS symptoms and SOC remained stable after all adjustments.

\section{Discussion}

This study aimed to investigate the associations between physical inactivity and health complaints in relation to post-traumatic stress symptoms, behavioral factors, and eating patterns as well as sense of coherence among eighth-grade girls enrolled in secondary schools in Kaunas.

Although adolescence is traditionally viewed as a period of good physical health, teenagers frequently report psychosomatic symptoms. To our knowledge this is the first study to investigate the associations between physical inactivity and health complaints in relation to PTS symptoms in adolescent girls. We found that weekly health complaints were fairly prevalent among these girls and that the most frequent complaint was "morning fatigue". Our results corroborate the findings from other studies 8,21 , indicating that headache, stomachache, and illness were experienced by nearly one-third of the girls, and that girls' complaints of pain and perceived health problems increased with age 22 . In our study, $12.2 \%$ of the girls were physically inactive, similar to the prevalence found in an HBSC survey of 20 European countries 5, although the findings from an Asian country provide much lower levels among seventh-grade girls (3.5\%) 13, probably due to cultural differences in leisuretime activity.

In recent years much attention has been paid to research on the associations between lifetime PTS symptoms and various subsequent effects (adverse health behaviors, mental health problems). Longitudinal research has identified adolescence as a developmental period in which individuals are particularly susceptible to experiencing trauma and, in turn, developing PTSD 7. Many studies confirm that PTS symptoms are quite prevalent among youth and are associated with health problems 9,10,23. Our study supported this idea, as the associations between all the investigated health complaints and PTS symptoms were significant $(\mathrm{p}<0.001)$. Studies of neurological and cognitive factors related to adolescent development indicate that capacities involved to higher-level brain functioning develop during adolescence 7 . The long-term side effects of 
Crude and adjusted associations between physical inactivity and health complaints in a sample of Lithuanian adolescent schoolgirls, 2012.

\begin{tabular}{|c|c|c|c|c|c|c|c|c|c|c|}
\hline & \multicolumn{2}{|c|}{ Crude } & \multicolumn{2}{|c|}{ Model I } & \multicolumn{2}{|c|}{ Model II } & \multicolumn{2}{|c|}{ Model III } & \multicolumn{2}{|c|}{ Model IV } \\
\hline & OR & $95 \% \mathrm{Cl}$ & OR & $95 \% \mathrm{Cl}$ & OR & $95 \% \mathrm{Cl}$ & OR & $95 \% \mathrm{Cl}$ & OR & $95 \% \mathrm{Cl}$ \\
\hline Insufficient physical activity & 1.83 & $1.14-2.94$ & 1.71 & $1.05-2.80$ & 1.62 & $0.98-2.70$ & 1.56 & $0.93-2.59$ & 1.45 & $0.84-2.49$ \\
\hline PTS symptoms & & & 9.21 & $4.76-17.8$ & 8.18 & $4.21-15.9$ & 8.27 & $4.25-16.1$ & 3.07 & $1.51-6.24$ \\
\hline Smoking & & & & & 2.08 & $1.20-3.63$ & 2.05 & $1.18-3.58$ & 1.23 & $0.68-2.23$ \\
\hline Daily alcohol intake & & & & & 3.24 & $1.33-7.93$ & 3.37 & $1.37-8.26$ & 2.56 & $0.99-6.74$ \\
\hline Daily fresh vegetables (no) & & & & & & & 1.30 & $0.94-1.80$ & 1.41 & $0.99-2.00$ \\
\hline Sense of coherence (continuous) & & & & & & & & & 0.89 & $0.87-0.91$ \\
\hline
\end{tabular}

95\% Cl: 95\% confidence interval; OR: odds ratio; PTS: posttraumatic stress.

Model I: adjusted for PTS symptoms; Model II: adjusted for PTS symptoms, smoking, daily alcohol intake; Model III: adjusted for PTS symptoms, smoking, daily alcohol intake, daily consumption of fresh vegetables; Model IV: adjusted for PTS symptoms, smoking, daily alcohol intake, daily consumption of fresh vegetables, sense of coherence.

the neurological changes associated with PTSD during adolescence are still largely unknown but have been linked to disorders such as attentiondeficit hyperactivity disorder and behavioral disorders 24 . Data from a large cross-sectional study of teenage females also found that PTSD diagnosis in adolescence was associated with poorer health outcomes, particularly more chronic conditions and reproductive health problems 9 .

In our study, physical inactivity was significantly associated with health complaints, corroborating other studies, indicating a positive effect of physical activity on general health status $4,5,11,25,26$. The majority of studies investigated the role of physical activity in the relationship between school-related stress and adolescent health complaints 27,28 . Scientists have come to a consensus with ample evidence supporting the view that physical activity is linked to improved physical fitness, psychological health and wellbeing, and positive health-related behaviors 22 . Our study focused on a quite new potential variable, partially explaining the associations between insufficient physical activity and health complaints, namely PTS symptoms, which were positively associated with level of physical activity (Table 1). The new finding in our study was that PTS symptoms mediated the associations between physical inactivity and health complaints. Studies of predictors of physical inactivity in youth have usually measured social and behavioral variables $4,29,30$. Our study investigated the effect of PTS symptoms, smoking, alcohol intake, and diet in the associations between physical inactivity and health complaints, and the effect of PTS symptoms remained stable after all adjustments. The inverse association between alcohol intake and physical activity was shown in this study and in some previous studies 31, although other authors have found a positive relationship between physical activity and alcohol use ${ }^{16}$. Among girls, socialization is probably not associated with drinking and sports to the same degree as for boys. Our study found that daily alcohol intake was associated with leisuretime physical inactivity among girls. When we included smoking, daily alcohol intake, and daily consumption of fresh vegetables in the analyses, the associations between physical inactivity and health complaints weakened, and after inclusion of sense of coherence in the logistic regression model, the adjusted OR dropped to 0.25 (Table 2). Although SOC in adolescence is still prone to change, it showed an independent significant effect, indicating the construct's importance in maintaining good health status. Other authors have also concluded that although SOC may not be fully developed in adolescents, it appears to be a meaningful concept for investigation in this age group ${ }^{32}$.

Recent school-based programs to promote physical activity and fitness among adolescents have concluded that physical activity improves self-rated health 33 and shows positive effects on behavior and physical health status, but the magnitude of the effect is generally small 34 . The reason for insufficient effect of intervention programs may be that physical inactivity can be associated with mental health problems among adolescents, so multifactorial health promotion strategies should be implemented in the future.

Adolescents' mental health problems have been studied in recent years 8,21 , and cognitivebehavioral skills-building interventions with 
20 minutes of physical activity integrated into a health course has been suggested to improve physical activity and mental health outcomes (depression, anxiety) 35. Adolescence is a developmental period in which exposure to trauma reaches its peak and as such it is a critical time for interventions aimed at preventing PTSD and mitigating sequelae. We thus suggest including PTS screening in studies on mental health among adolescents. We recommend using cognitive-behavioral therapy to reduce PTS symptoms among adolescents, since such symptoms can lead to poor general health in the future. Studies have confirmed that health problems associated with PTSD in adolescence may continue in adulthood.

The current study has several limitations resulting from self-reported data and the crosssectional design. Although it has been suggested that self-reports can be used reliably to evaluate problems in adolescence, the impact of factors such as inconsistent answers, recall bias, social desirability, and faking cannot be ruled out entirely. The study design did not include the as sessments of care-seeking related to health complaints, the use of clinical diagnostic information based on medical examination, or additional sources of information (e.g. parents/guardians). The cross-sectional study did not allow conclusions on a causal relationship between factors.

In conclusion, this study demonstrated associations between insufficient physical activity and health complaints in a sample of adolescent girls. The associations were mediated by PTS symptoms, indicating the need to address mental health problems in adolescents.

\section{Resumen}

El objetivo del estudio fue investigar la asociación entre inactividad física y molestias de salud en relación con síntomas de estrés postraumático (SEP), factores nutricionales y de comportamiento, así como el sentido de coherencia (SDC) entre las niñas de octavo grado. Una muestra aleatoria de las niñas $(N=862)$ fueron entrevistadas de forma anónima sobre las quejas de salud, el nivel de actividad física, los SEP, escala SOC de Antonovsky, conductas de salud, los hábitos alimentarios. Todas las quejas de salud se asociaron significativamente con la inactividad física. El odds ratio (OR) no ajustado de la inactividad física para las quejas de salud fue de 1,67 (IC95\%: 1,09-2,56), después del ajuste para los SEP se redujo a 1,57 (IC95\%: 0,95-2,45); tras los ajustes debidos al tabaco, bebidas alcohólicas diarias, verduras frescas, el SDC disminuyó a 1,25 (IC95\%: 0,76-2,04). Se encontró una asociación significativa entre la inactividad y las quejas de salud fueron medidas por los SEP.

Actividad Motora; Trastornos de Estrés

Postraumático; Adolescente

\section{Contributors}

R. Malinauskas planned the article, arranged the sections, and revised the final version. V. Malinauskaiene planned the article, arranged the sections, drafted the preliminary version, and revised the final version.

\section{Acknowledgments}

The authors wish to thank the students for their participation and the school nurses who assisted with the study's data collection. 


\section{References}

1. Gerber M, Pühse U. Review article: do exercise and fitness protect against stress-induced health complaints? A review of the literature. Scand J Public Health 2009; 37:801-19.

2. Lochbaum MR, Lutz RS, Sell S, Ready A, Carson T. Perceived stress and health complaints: an examination of the moderating roles of personality and physical activity. Percept Mot Skills 2004; 99(3 Pt 1):909-12.

3. Lämmle L, Worth A, Bös K. A biopsychosocial process model of health and complaints in children and adolescents. J Health Psychol 2011; 16:226-35.

4. Galán I, Boix R, Medrano MJ, Ramos P, Rivera F, Pastor-Barriuso R, et al. Physical activity and selfreported health status among adolescents: a cross sectional population-based study. BMJ Open 2013; 3:e002644.

5. Petronyte G, Zaborskis A. The influence of individual and regional factors on association between leisure time physical activity and psychological complaints among adolescents in Europe. Cent Eur J Public Health 2009; 17:215-9.

6. Gerson R, Rappaport N. Traumatic stress and posttraumatic stress disorder in youth: recent research findings on clinical impact, assessment, and treatment. J Adolesc Health 2013; 52:137-43.

7. Nooner KB, Linares LO, Batinjane J, Kramer RA, Silva R, Cloitre M. Factors related to posttraumatic stress disorder in adolescence. Trauma Violence Abuse 2012; 13:153-66.

8. Stickley A, Koyanagi A, Koposov R, McKee M, Roberts B, Ruchkin V. Peer victimisation and its association with psychological and somatic health problems among adolescents in northern Russia Child Adolesc Psychiatry Ment Health 2013; 7:15.

9. Seng JS, Graham-Bermann SA, Clark MK, McCarthy AM, Ronis DL. Posttraumatic stress disorder and physical comorbidity among female children and adolescents: results from service use data. Pediatrics 2005; 116:e767-76.

10. Ruchkin V, Schwab-Stone M. A longitudinal study of somatic complaints in urban adolescents: the role of internalizing psychopathology and somatic anxiety. J Youth Adolesc 2013; 43:834-45.

11. Kim YS, Park YS, Allegrante JP, Marks R, Ok H, Cho $\mathrm{KO}$, et al. Relationship between physical activity and general mental health. Prev Med 2012; 55:45863.

12. Marshall VJ, Kalu N, Kwagyan J, Scott DM, Cain GE, Hill K, et al. Alcohol dependence and health care utilization in African Americans. J Natl Med Assoc 2013; 105:42-9.

13. Wang MP, Ho SY, Lo WS, Lai MK, Lam TH. Smoking is associated with poor self-rated health among adolescents in Hong Kong. Nicotine Tob Res 2012; 14:682-7.

14. Rottenberg J, Yaroslavsky I, Carney RM, Freedland KE, George CJ, Baji I, et al. The association between major depressive disorder in childhood and risk factors for cardiovascular disease in adolescence. Psychosom Med 2014; 76:122-7.
15. Bigelow A, Villarruel A, Ronis DL. The relationship of alcohol use and physical activity from an ecologic perspective. J Spec Pediatr Nurs 2014; 19:28-38.

16. Coutinho VM, Heimer MV. Senso de coerência e adolescência: uma revisão integrativa de literatura. Ciênc Saúde Coletiva 2014; 19:819-27.

17. Weiss DS. The Impact of Event Scale-Revised. In: Wilson JP, Keane TM, editors. Assessing psychological trauma and PTSD. 2nd Ed. New York: Guilford Press; 2004. p. 168-89.

18. Godin G, Shephard RJ. Godin leisure time exercise questionnaire. Med Sci Sports Exerc 1997; 29:36-8.

19. Antonovsky A. The structure and properties of the sense of coherence scale. Soc Sci Med 1993; 36:725-33.

20. Zaborskis A, Lagunaite R, Busha R, Lubiene J. Trend in eating habits among Lithuanian schoolaged children in context of social inequality: three cross-sectional surveys 2002, 2006 and 2010. BMC Public Health 2012; 12:52.

21. Forero R, McLellan L, Rissel CH, Bauman A. Bullying behaviour and psychosocial health among school children in New South Wales, Australia: cross sectional survey. BMJ 1999; 319:344-8.

22. Sundblad GB, Jansson A, Saartok T, Renström P, Engström LM. Self-rated pain and perceived health in relation to stress and physical activity among school-students: a 3-year follow-up. Pain 2008; 136:239-49.

23. Kerig PK, Ward RM, Vanderzee KL, Arnzen Moeddel M. Posttraumatic stress as a mediator of the relationship between trauma and mental health problems among juvenile delinquents. J Youth Adolesc 2009; 38:1214-25.

24. DeBellis MD, Keshavan MS, Shifflet H, Iyengar S, Beers SR, Hall J, et al. Brain structures in pediatric maltreatment-related posttraumatic stress disorder: a sociodemographically matched study. Biol Psychiatry 2002; 52:1066-78.

25. Piko BF, Keresztes N. Self-perceived health among early adolescents: role of psychosocial factors. Pediatr Int 2007; 49:577-83.

26. Alricsson M, Domalewski D, Romild U, Asplund R. Physical activity, health, body mass index, sleeping habits and body complaints in Australian senior high school students. Int J Adolesc Med Health 2008; 20:501-12.

27. Haugland S, Wold B, Torsheim T. Relieving the pressure? The role of physical activity in the relationship between school-related stress and adolescent health complaints. Res Q Exerc Sport 2003; 74:127-35.

28. Gerber M, Pühse U. "Don't crack under pressure!” Do leisure time physical activity and self-esteem moderate the relationship between school-based stress and psychosomatic complaints? J Psychosom Res 2008; 65:363-9.

29. Tammelin T. A review of longitudinal studies on youth predictors of adulthood physical activity. Int J Adolesc Med Health 2005; 17:3-12. 
30. Singh GK, Kogan MD, Siahpush M, van Dyck PC. Independent and joint effects of socioeconomic, behavioral, and neighborhood characteristics on physical inactivity and activity levels among US children and adolescents. J Community Health 2008; 33:206-16.

31. Denver BV, Schulenberg J, Dworkin JB, O’Malley PM, Kloska DD, Bachman JG. Predicting risk-taking with and without substance use: the effects of parental monitoring, school bonding, and sports. Prev Sci 2012; 13:605-15.

32. Moksnes UK, Løhre A, Espnes GA.The association between sense of coherence and life satisfaction in adolescents. Qual Life Res 2013; 22:1331-8.

33. Kahlin Y, Werner S, Alricsson M. A physical activity program in Swedish physically inactive female high school students: a controlled intervention study. J Phys Act Health 2013; 11:1162-9.
34. Dobbins M, Husson H, DeCorby K, LaRocca RL. School-based physical activity programs for promoting physical activity and fitness in children and adolescents aged 6 to 18. Cochrane Database Syst Rev 2013; 2:CD007651.

35. Melnyk B, Kelly S, Jacobson D, Arcoleo K, Shaibi G. Improving physical activity, mental health outcomes, and academic retention in college students with Freshman 5 to thrive: COPE/Healthy lifestyles. J Am Assoc Nurse Pract 2014; 26:314-22.

Submitted on 27/May/2014

Final version resubmitted on 15/Nov/2014

Approved on 04/Dec/2014 